\title{
Nasilne meje, varnostnizacija in kriminalizacija solidarnosti
}

\begin{abstract}
Avtonomijo socialnega dela ogroža varnostnizacija, kije oblika strukturnega nasilja nad migranti in begunci. Policijska potiskanjanaevropskih mejah so kršitevmednarodnih standardovin pravice do pravic ljudina poti. V takem rasističnem družbenem kontekstu so tudiskupine in posamezniki, kise solidarizirajo z migranti, preganjani in ustrahovani. Oblast solidarnost prikaže kot zločin. V članku avtorica na podlagi metod opazovanja z udeležbo in avtoetnografije išče mesto socialnega dela, ki neenakosti in nasilja ne bo povečevalo, temveč upoštevalo načela stroke.
\end{abstract}

Ključne besede: migracije, begunci, avtonomija, policijsko potiskanje, socialno delo, aktivizem.

Dr. Jelka Zorn je izredna profesorica na Fakulteti za socialno delo Univerze v Ljubljani in No Border aktivistka. Kontakt: jelka.zorn@fsd.uni-lj.si.

\begin{abstract}
Violent borders, securitization, and criminalization of solidarity
Autonomy of social work is undermined by securitization, which is a form of structural violence against migrants and refugees. Police pushbacks at the European borders are violation of international standards and the right to have rights. In such racist social environment, groups and individuals, who show solidarity with migrants, are also criminalised and threatened. Authorities consider solidarity a crime. The author combines research methods of observance participation and auto-ethnography. These are applied to search the position of social work in order not to reproduce inequalities and violence, but on the contrary, to conceptualize and work in line with professional values.
\end{abstract}

Key words: migration, refugees, autonomy, pushback, social work, activism.

Jelka Zorn, PhD, is an Associate Professor at the Faculty of Social Work, University of Ljubljana, and a No Border activist. Contact: jelka.zorn@fsd.uni-lj.si

\section{Uvod $^{1}$}

Begunce in migrante opredeljuje prehod meje (Jones, 2017). Meje zaznamujejo formalni predpisi in simbolni pomeni razločevanja in pripadnosti. Za socialno delo so meje pomembne, ker niso le razmejitev enega državnega ozemlja od drugega, temveč so vključene v državo blaginje, v socialne, zdravstvene, izobraževalne in druge javne ustanove in storitve, $v$ dostop do trga dela in delavskih pravic ter prečijo združevanje družin (Balibar, 2007; Humphries, 2004).

Meje obeležujeta vladavina policije in diskurz varnostnizacije. Paradoks je $v$ tem, da varnostnizacija ne prinaša več varnosti, ampak nasprotno, bolj tvegane prehode meje, več smrtih žrtev, več ločenih družin in več policijskega nasilja (Zaviršek, 2017a). Evropska unija ima najnevarnejšo mejo na svetu. Od leta 2014 do konca leta 2019 je na evropskih mejah, med drugim tudi v Sredozemskem morju kot največjem mejnem pokopališču na svetu, umrlo 20.000 ljudi (IOM, 2020). Samo v enem letu (2019) je tu življenje izgubilo

1 Besedilo je nastalo v okviru projekta ARRS »Socialno delo kot nosilec procesov družbenega vključevanja in socialne pravičnosti v Sloveniji « (P5-0058) in v okviru projekta »Evropski režim iregulariziranih migraciji na periferiji EU: Od etnografije do pojmovnika « (Hrvatska zaklada za znanost, IP-2019-04-6642). Zahvaljujem se Asji Hrvatin in Maji Ivačič za številne razprave o avtonomiji socialnega dela in migraciji ter komentiranje članka v nastajanju. 
najmanj 2033 ljudi (1885 v Sredozemskem morju in 148 na evropskih tleh). Povprečno je umrlo šest oseb na dan.

To je vojna proti revnim z globalnega juga. $V$ tej vojni se evropske vlade in policije $\mathrm{z}$ nakopičeno tehnično in zakonodajno infrastrukturo nadzora bojujejo proti migrantkam in migrantom, med katerimi so tudi otroci. V nasprotju z vladnim aparatom nadzora pa so v tem boju glavna »orožja « ljudi na poti mobilni telefoni, volja do (boljšega) življenja, zlasti pa skupno-v-gibanju (mobile commons). Izraz skupno-v-gibanju se nanaša na alternativni način potovanja $\mathrm{z}$ delitvijo informacij in medsebojno skrbjo, ki ga ne more ustaviti ne ograja, ne policijska potiskanja na meji, ne ilegalizacija migrantskih življenj (Papadopoulos in Tsianos, 2013).

Metoda raziskovanja je priložnostno večletno opazovanje $\mathrm{z}$ udeležbo $\mathrm{v}$ avtonomnih prostorih, ki jih zaznamujejo protirasistične solidarnostne prakse v Ljubljani (zlasti v Rogu), Beogradu (januar 2017), Šidu (februar 2018), Veliki Kladuši (november 2019 in januar 2020) in drugod. Poleg metode opazovanja z udeležbo sem uporabljala tudi avtoetnografski pristop. Ta vključuje sodelovanje v solidarnostnih praksah in kriminalizacijo, ki sem jo doživela zaradi prevažanja dveh afganistanskih državljanov na Hrvaškem z namenom preprečitve policijskega potiskanja junija 2017. Hranim dnevniške zapise, tudi zapisnik sodnika za prekrške iz Vukovarja. Aretacija in plačilo kazni za nekaj, kar smo socialne delavke - aktivistke poimenovale direktno socialno delo, sta zahtevala temeljito spraševanje o hegemonih družbenih odnosih in etiki socialnega dela.

Struktura članka je taka, da najprej opredelim družbeni kontekst, in sicer se osredotočim na vidike strukturnega in neposrednega policijskega nasilja nad ljudmi na poti. S pomočjo koncepta organizirane hipokrizije analiziram sistematično onemogočanje podajanja vloge za azil in s tem pravice do azila. Pomemben poudarek članka je, da evropske meje niso le utelešenje strukturnih neenakosti. Zaznamujejo jih tudi prostorska nepokorščina migrantk in migrantov ter njihovi boji za avtonomijo in človekove pravice ter solidarnostne prakse (Tazzioli, 2018).V članku opredelim solidarnost in jo povežem s pojmi skupnosti in skupnostnega kuhanja. Razpravljam o kriminalizaciji solidarnostnih praks in ustvarjanju sovražnega okolja tako za migrantke in migrante kot domačine. Sklenem z mislijo o težavnosti transformacije družbenih odnosov.

\section{Varnostnizacija kot strukturno nasilje}

Nasilje, ki ga doživljajo migranti in begunci na mejah in na sploh v zvezi z nadzorom priseljevanja, lahko razdelimo v strukturno in neposredno (policijsko) nasilje. Johan Galtung (1969) meni, da lahko v primeru neposrednega nasilja identificiramo konkretne povzročitelje, v primeru strukturnega nasilja pa ni nujno, da v strukturi obstaja oseba, ki neposredno poškoduje drugo osebo. »Nasilje je vgrajeno v strukturo in se kaže kot neenako razmerje moči in posledično kot neenake življenjske možnosti« (Jones, 2017, str. 18). Strukturno nasilje je institucionalizirana neenakost.

Za strukturno nasilje na področju migracij se je uveljavil izraz varnostnizacija. Gre za diskurz in sistem ukrepov, ki določeno kategorijo ljudi izključi 
iz družbe, tako da jo opredeli kot nevarnost, na primer za kulturne vrednote, socialne transferje, javno varnost, zdravje ali trg dela (Huysmans, 2000, str. 771). Pomeni vladavino policije na področju migracij in je v Zahodni Evropi značilna od osemdesetih let 20. stoletja. Huysmans, ki je pisal pred terorističnim napadom na stolpnici Svetovnega trgovinskega centra v New Yorku leta 2001, je varnostnizacijo povezal s šovinizmom (nacionalizmom) države blaginje, pozneje pa so varnost začeli povezovati s protiterorističnim diskurzom.

Varnostnizacija se je začela kot državna politika za zavarovanje delovnih mest in delavskih pravic, ko polna zaposlenost prebivalstva v Zahodni Evropi (zaželeni destinaciji mnogih) ni bila več samoumevna. Tako so migranti in prosilci za azil vse bolj videni ne kot tekmeci ali tovariši, temveč kot nelegitimni prejemniki socialno-ekonomskih pravic. Nelegitimne so postale tudi njihove zahteve po zaposlitvi in enakih pravicah. V vsakdanjem rasističnem govoru ta šovinizem države blaginje odzvanja v mišljenju: »Najprej moramo poskrbeti za naše revne ljudi «. ${ }^{2}$ Socialni transferji in država blaginje so videni kot magnet za migrante v Evropsko unijo, v zvezi s tem pa se je uveljavila dikcija »lažnih « beguncev in begunk, to so osebe, ki naj bi izkoriščale azilni sistem za možnost vstopa v državo in iskanje zaposlitve (Huysmans, 2000, str. 771).

Strinjam se z Beth Humphries (2004), da vloga socialnega dela ne bi smela postati policijska v pomenu, da nadzorujemo in izključujemo ljudi na podlagi njihovega statusa. Namreč, avtonomija socialnega dela - da nismo del nadzora - ni dana sama po sebi. Tako na primer 5. člen Zakona o socialnem varstvu (2019) določa, da so upravičenci tega zakona načelno državljani Republike Slovenije in tujci z dovoljenjem za stalno prebivanje. Zakon o mednarodni zaščiti osebe s statusom begunca $v$ večini socialnih pravic sicer izenači z državljani, vendar država vsako leto prizna ta status le okoli 100 vlagateljem in njihovim družinam. ${ }^{3}$ Vsi drugi so izključeni. Ta meja dostopa do zdravstvenih, socialnih in drugih pravic je nevidna za »nas « (državljane), a boleča realnost za tiste, ki jo občutijo v vsakdanjem življenju.

Poleg zakonskih zamejitev gre tudi za simbolno mejo drugosti (Zaviršek, 2017b). Zato vlogo socialnega dela vidim kot tisto, ki se pridruži boju za enake pravice in enako dostojanstvo vseh, tudi priseljenih oseb, ne glede na njihove statuse in razloge za selitev (beg pred revščino, okoljsko degradacijo, vojno ali selitev zaradi povsem subjektivnih razlogov). Velja pa tudi obratno: od širine opredelitve socialnega dela je odvisno, ali socialno delo ohranja ali celo utrjuje meje (ker je dostop do socialnih storitev, zlasti socialnih transferjev, odvisen od osebnih pravnih statusov) ali pa kot socialno delo vidimo tudi avtonomne solidarnostne prakse. Te imajo transformativni potencial, ker razvijajo pripadnost in skupnost ne glede na pravne statuse. $V$ tem pogledu jih vidim kot alternativo državnim in tudi humanitarnim organizacijam, saj te pogosto ohranjajo obstoječa razmerja moči (Fassin, 2012).

2 »Naši revni ljudje « so denimo nekatere romske skupnosti, a vendar imajo izkušnje izključevanja, ne pa razumevanja in podpore.

3 Od leta 2015 do konca 2019 je Ministrstvo za notranje zadeve priznalo status mednarodne zaščite 560 osebam (Urad Vlade RS za oskrbo in integracijo migrantov, 2020). 


\section{Policijska potiskanja kot neposredno nasilje}

Od leta 2016 o policijskem potiskanju (ang. push-back) in nasilju na balkanski poti in v Grčiji poroča neodvisna mreža nevladnih organizaciji Border Violence Monitoring Network (b.d.). Do novembra 2020 so na svoji spletni strani objavili 884 pričevanj migrantov. Ta pričevanja se nanašajo na 11.000 ljudi. Iz pričevanj migrantov so razvidne dejavnosti policije pri ogrožanju človeških življenj ter sodelovanje slovenske in hrvaške policije kot »vratark « EU. Policijsko nasilje obsega: poniževanje in surovo ravnanje, mučenje, pretepanje, brcanje, uničevanje mobilnih telefonov, prisilno slačenje ter odvzem oblek in obutve, kraje denarja, uporabo policijskih psov in verižna potiskanja nazaj po balkanski poti in s tem onemogočanje začetka postopka za pridobitev mednarodne zaščite v Evropski uniji.

Po mednarodnem pravu so policijska potiskanja nedovoljena, a so vendar sistematična policijska praksa na balkanski poti. Border Violence Monitoring Network (b.d.) opredeli potiskanja kot del neuradnega migracijskega režima Evropske unije in se razlikujejo od deportacije: »Policijska potiskanja so neformalni čezmejni izgoni (brez uradnih postopkov) posameznikov ali skupin v drugo državo.« 0 njih poročajo migrantke in migranti, mediji, organizacije za varstvo človekovih pravic in poslanci v Evropskem parlamentu (2020), a vendar jih vlade zanikajo oziroma opravičujejo z razlikovanjem med begunci in ekonomskimi migranti.

Slovenska policija potiskanja opravičuje tudi s sklicevanjem na »sporazum o vračanju na Hrvaško « (Sporazum med Vlado Republike Slovenije in Vlado Republike Hrvaške o izročitvi in prevzemu oseb, katerih vstop ali prebivanje je nezakonito, 2006). Ko ljudje pridejo v stik s slovenskimi policisti, ne le na sami meji, temveč tudi v notranjosti države, policisti po navadi zapišejo njihove osebne podatke (po pričevanju migrantov včasih vzamejo prstne odtise), potem pa jim ne glede na izraženo prošnjo po mednarodni zaščiti pogosto rečejo, da v Sloveniji »azila ni «, jih odpeljejo na mejo in predajo hrvaškim policistom, ti pa naprej srbskim ali bosanskim oblastem. Enaka je praksa na Hrvaškem, le da so potiskanja iz Hrvaške pogostejša in nasilnejša. Hrvaška se bo morala zagovarjati na Evropskem sodišču za človekove pravice. Pritožbo so vložili trije sirski državljani, med njimi mladoletnik, potem ko jih je jeseni 2018 - kot tisoče drugih - hrvaška policija potisnila nazaj v Bosno, ne da bi lahko podali vlogo za azil (ECCHR, 2020). Ljudje na skrivni prestop meje čakajo v Srbiji ali Bosni in Hercegovini, ki obe mejita na Hrvaško. Šestnajstletnemu fantu, Palestincu, je tako po številnih potiskanjih hrvaške policije le uspelo priti do Slovenije, tam pa je policistom na kratko pojasnil svojo situacijo in prosil za mednarodno zaščito v Sloveniji.

Policist je izpolnil formular in vpisal mojo letnico rojstva 2002. Potem je odšel po nov formular, tistega od prej uničil in izpolnil novega s ponarejeno letnico rojstva 2000. Rekel sem policistu »please asylum, I'm a minor «. Ampak nič ni pomagalo. Dali so me hrvaški policiji in me peljali v azilni dom v Adaševcih [v Srbiji]. (Dnevniški zapis, 11. 2. 2018, Šid)

Fanta sem spoznala na mrazu februarja 2018 na srbsko-hrvaški meji, razočaranega nad zaščito pravic otrok v Evropi, a odločenega za ponovne poskuse skrivnega prestopa meje. Čez več mesecev je fantu uspelo priti v eno od držav 
znotraj schengenskega območja. Medtem ko vlade obtožujejo za ranljivost migrantov tihotapce, ljudje na poti poročajo o nezakonitem ravnanju policije, kot kaže tudi dnevniški zapis.

V zvezi s potiskanji so preiskavo opravili Varuh človekovih pravic (2018), Amnesty International Slovenia (2018), Pravno-informacijski center nevladnih organizacij (Regvar, 2018) in Info Kolpa (2019), stanje na področju pravic migrantk in migrantov (na mejah) pa kontinuirano spremlja Delovna skupina za azil (2020). Kot ocenjuje Are You Syrious (Medium, 2020), je bilo v zadnjih dveh letih iz Slovenije na Hrvaško potisnjenih 16.000 ljudi. Sodišče v Genovi je maja 2020 prepovedalo vračanja prosilcev za azil iz Italije v Slovenijo z argumentom nehumane obravnave in ilegalnih policijskih potiskanj na Hrvaško, od tam pa v Bosno ali Srbijo (Delovna skupina za azil, 2020).

Navajam primer za ponazoritev policijskega diskurza, s katerim opravičujejo režim zavračanja ljudi. Ministrica za notranje zadeve je na tiskovni konferenci povedala, da jih »žalosti in skrbi dejstvo, da se zlahka in veliko bolj kot ugotovitvam MNZ in Policije verjame izjavam drugih subjektov, med temi tudi nevladnim organizacijam in nenazadnje tudi tujcem, ki prihajajo« (Ministrstvo za notranje zadeve RS, 2018). Takole je pojasnila (prav tam):

Želela bi še enkrat poudariti, da se policija ne obrača stran, da sliši namere zaprositi za mednarodno zaščito in da je izjava tujca, samostojna, individualna izjava tujca tista, ki prevaga v policijskih postopkih. Je pa res, da niso samo nevladniki in novinarji tisti, ki svetujejo tujcem, naj izrazijo namero zaprositi za mednarodno zaščito, ampak so to predvsem tihotapci, ki postopek oziroma zlorabo postopka vključujejo v svoj poslovni model tihotapljenja čez državno mejo. [...] zloraba azilnega postopka [je] najbolj [...] uporabljen način prestopanja državne meje v RS.

Tihotapci in nevladne organizacije so opredeljeni kot »krivci « za informiranje ljudi o pravnih postopkih. Kot da bi bila upravičenost do začetka postopka za azil odvisna od vira informacij. Gre pa tudi za shizofreno situacijo, v kateri naj bi bilo možno oboje hkrati: uresničevanje pravice do mednarodne zaščite in varovanje meje pred begunci oziroma migranti. Ta antagonizem je na videz razrešen $z$ diskurzom in praksami ločevanja beguncev in migrantov na dve kategoriji. Enak diskurz uporablja UNHCR Slovenija (b.d.). To razlikovanje naj bi policijskim potiskanjem »migrantk in migrantov« dalo videz zakonitosti in legitimnosti, kot pojasnim v nadaljevanju.

\section{Razlikovanje migrantov in beguncev kot organizirana hipokrizija}

Čeprav sta varovanje ozemlja in preprečevanje nezakonitih migracij legitimni pravici vsake države, je pomembno, da še tako strogo upravljanje meja ne prepreči osebam, ki iščejo mednarodno zaščito, dostopa do ozemlja. [...] Danes so migracijska gibanja izredno zapleten pojav, ki ne vključujejo le beguncev, ampak tudi na milijone migrantov. [...] Njihov obup in željo po boljšem življenju pogosto izkoristijo tihotapci, ki so iz stiske drugih ljudi naredili milijonski posel. (UNCHR Slovenija, b.d.) 
Citat je značilen primer tako pripisovanja odgovornosti za migracijo tihotapcem kot nasprotujočih si zahtev po varovanju meje pred prihodom migrantk/ migrantov in hkrati po omogočanju postopkov mednarodne zaščite. Namesto možnosti za mednarodno zaščito ljudje na mejah večinoma doživijo mednarodno zavračanje v obliki verižnih potiskanj nazaj po balkanski poti. Zaradi (takega) nadzora mej in zavrnjenih vlog za mednarodno zaščito sva z Uršulo Lipovec Čebron (Lipovec Čebron in Zorn, 2016) ugotovili, da je azil farsa. Azilni sistem je neločljivo spojen $\mathrm{z}$ (nasilnim) mejnim režimom.

Govor o pravici do azila in hkrati o nadzoru meje lahko opredelim s pojmom organizirane hipokrizije. Eugenio Cusumano (2018) je ta pojem uporabil pri analizi (ne)reševanja migrantk in migrantov iz Sredozemskega morja. Analiziral je Frontexovi operaciji Triton in Sofio - operaciji »skupne varnostne in obrambne protitihotapske misije pri Pomorski mediteranski sili EU« - in ugotovil, da obstaja prepad med retoriko in dejansko prakso, ko gre za nadzor meje in reševanja iz morja. Teh dveh tendenc, humanitarizma (reševanja iz morja) in nadzora meje (odganjanja migrantov, nereševanja iz morja) med sabo ni mogoče pomiriti, gre za nasprotujoče si cilje Frontexa in drugih misij EU. Tudi cilji slovenske in hrvaške policije, ki nadzirata schengensko mejo, si nasprotujejo. Policija naj bi varovala človekove pravice (omogočala začetek postopka za azil) in hkrati nadzirala meje (torej onemogočala prihod migrantk/migrantov).

Organizacije, ki imajo nasprotujoče si cilje, zadrego rešujejo tako, da dejanja ločijo od retorike (Cusumano, 2018, str. 2). Zunanja politika Evropske unije razglaša moralno zavezanost zaščiti človekovih pravic in spoštovanju mednarodnega prava (Cusumano, 2018, str. 5). Evropska unija velja za normativno in etično svetovno silo, saj so človekove pravice, tudi pravica do mednarodne zaščite, in postopki zagotavljanja teh pravic opredeljeni v zakonodajah držav Evropske unije in se do določene mere izvajajo.

Konflikt med pravico do azila in nadzorom meje (to pomeni preprečevanje prehodov meje) vlade razrešijo z neživljenjsko delitvijo na dve domnevno ločeni kategoriji: na begunce (ki imajo pravice) in ekonomske migrante (ki pravic nimajo), kot je razvidno iz citata UNHCR Slovenije (b.d.) na začetku tega poglavja. Policija ljudi pretepa in potiska nazaj po balkanski poti zato, ker so »migranti« in ne »begunci«. Nadzora meje in preprečevanja »poslovnega modela tihotapcev« ni mogoče izvajati hkrati s spoštovanjem pravic begunk in beguncev. Enako shizofrena je situacija glede zapora za migrante (olepšano imenovanega center za tujce). V razčlovečenje in omejevanje svobode policija uvaja diskurz človekovih pravic, ki zaprtim migrantkam in migrantom v ničemer ne pomaga. »Pomaga« edino socialnim delavkam in družbi na sploh, da tako ustanovo tolerirajo, saj jo poznajo le na retorični ravni policije, ne pa skozi oči tam zaprtih (Zorn, 2006).

\section{Solidarnost, migracije, socialno delo}

Kljub vladavini policije pa perspektiva socialnega dela omogoča videti, da na mejah in v notranjosti držav potekajo boji migrantk in migrantov za pravice do azila, svobode, človečnosti, mobilnosti, življenja, združevanja družin ipd. Ti boji so: prostorska nepokorščina migrantov (potujejo po skrivnih poteh 
brez državnega dovoljenja); strategije vključevanja v novo družbo od spodaj in politično delovanje (protesti, peticije, pričevanja, medijske kampanje); in skupnostno delo (v skvotih, nevladnih organizacijah, kulturnih dejavnostih ipd.). Prizadevanju migrantov se pridružujejo skupine »domačega« prebivalstva, denimo v avtonomnih prostorih Roga (gl. Fućak, 2017). Gre za vključujoče prakse, povezane s socialnim delom, saj gre za ista načela samoodločbe, krepitve moči in skupnostnega dela. Bolj ko se socialne delavke povežemo z migrantkami in migranti, bolj razvijamo avtonomijo socialnega dela, saj izstopimo iz okvirov pravnih statusov. To je povezano s solidarnostjo, zato $\mathrm{v}$ nadaljevanju opredelim pojem solidarnosti in ga povežem z migracijami, kuhanjem in skupnostnim delom.

Koren latinske besede solidus pomeni »cel, trden, nedeljen«, metaforično pa »zaupanja vreden, pristen«. Francoska skovanka solidarité s konca 18. stoletja pomeni »skupne interese in odgovornosti « (Online Etymology Dictionary, b.d.). Najpogosteje solidarnost raziskujejo na področju zgodovine delavskega gibanja ter protirasističnih in protikolonialističnih gibanj. $V$ zadnjih letih se pojem vse več uporablja v kontekstu kriminalizacije neodvisnih solidarnostnih iniciativ. Solidarnost ustvarja nove politične odnose in realnosti, ki jih razvijajo marginalizirane skupine (Dadusc in Mudu, 2020). V primerjavi z drugimi podobnimi izrazi, kot so pravičnost, državljanstvo, enakost, pa je termin solidarnost redkeje predmet akademskih analiz in definicij (Tazzioli in Walters, 2019).

Tazzioli in Walters (2019) spomnita na solidarnost kot evropski diskurz o delitvi bremena pri razporejanju begunk in beguncev po različnih državah EU. V tem kontekstu so begunci breme, izraz solidarnost pa je uporabljen za države, ki so solidarne z Italijo in Grčijo, kamor prispe največ beguncev, in ki naj bi te ljudi prevzele na svoja ozemlja. Vendar pa je treba biti kritičen do takega državnega prisvajanja, ki pojem solidarnosti sprevrača v privilegij. Zgodovinsko gledano se je solidarnost razvijala neodvisno od državnih politik, kajti ko gre za institucionalizacijo določenih praks, ni več smiselno govoriti o solidarnosti, temveč o ukrepih socialne politike (Dragoš, 2016).

Pri solidarnosti je pomemben pojem skupnosti, ki ni zgolj prepoznavanje ljudi takšnih, kakršni so, temveč je predvsem skupno delovanje za tisto, kar želimo postati skupaj (Hrvatin, 2016). Asja Hrvatin (2016: 72) poveže skupnost z bojem: »Skupnost (commonality) je lahko zgolj oblika boja, nikakor pa ne more biti stvar kapitalistične proizvodnje«. Skupnost ali skupno se uporablja tudi v glagolski obliki commoning, ker se s tem poudari proces postajanja skupnega. Vrednost skupnega ni v materialnih dobrinah, namenjenim deljenju, temveč $v$ samem procesu deljenja (Federici, 2019). Ta proces vključuje pripravljenost, da namenjamo čas sodelovanju, razpravljanju, pogajanju, skupnemu odločanju, obvladovanju konfliktov. Tako Hrvatin (2016) kot Ivačič (2019) raziskujeta graditev skupnosti v avtonomnih prostorih (skvotih) in s tem povezano samoorganizacijo. Gre za politično delovanje, reproduktivno in kreativno delo brez tržnih odnosov in brez države. Za področje migracij je relevanten tudi pojem skupno-v-gibanju (migration commons), ki sem ga že omenila. Označuje skupnosti podpore, medsebojne skrbi in alternativnega znanja ljudi na poti, da ostanejo mobilni in najdejo podporo tudi na novih destinacijah (Papadopoulos in Tsianos, 2013). 
Dva od načinov vzpostavljanja skupnosti sta skupno kuhanje in prehranjevanje, kot ju je opredelila Maja Ivačič (2019, str. 79), ki je tudi sama kuhala skupaj z migrantkami in migranti v Grčiji in drugod na balkanski poti: »Skupnostne kuhinje so oblike solidarnosti v praksi in živeta avtonomija.« V avtonomnih prostorih, tako začasnih kuhinjah kot skvotih, poteka samoorganizirano socialno delo: prepoznavamo lahko vrednote, načela in metode radikalnega in direktnega socialnega dela brez ločevanja na uporabnike in strokovne delavke (Flaker@Boj za, 2012; Fućak, 2017; Hrvatin, 2016; Ivačič, 2019).

Pri skupnem kuhanju in skupnem deljenju hrane je viktimizacija begunk in beguncev presežena, odnosi pomoči in prejemanja postanejo vzajemni, ljudje občutijo moč in pripadnost (Ivačič, 2019). Bivanjske razmere na poti so pogosto človeka nevredne - povzročajo travmo in razčlovečenje, zato je skupno kuhanje pravzaprav »ponovno učlovečenje« (prav tam). Ivačič (2019, str. 74) piše, da sta kuhanje in deljenje hrane na različnih mestih balkanske poti načina, »kako stopiti v stik z ljudmi na poti ter preko tega skupaj graditi gibanje proti rasistični politiki Trdnjave Evrope«. Ivačič (2019, str. 80) dodaja: »Z deljenjem hrane v tako surovih okoliščinah smo poskušale_i vzpostaviti vsaj eno točko dostojanstva in ljudem na poti pokazati, da jih podpiramo.«Skupni interesi in skupna odgovornost se gradijo skupaj z ljudmi na poti, se pravi, da skupnost ni etnična ali primordialistična povezava, nasprotno, gre za transverzalna zavezništva med migranti in domačini. Paulo Freire ([1968] 2019, str. 22) v klasičnem delu Pedagogika zatiranih solidarnost opredeli podobno:

Solidariziranje z zatiranimi je nekaj več kot nudenje pomoči tridesetim ali stotim, pri tem pa jih, vsemu navkljub čvrsto ohranjati v položaju odvisnosti. [...] Solidarnost je radikalen odnos, saj od tistih, ki hočejo biti solidarni, zahteva, da ponotranjijo položaj tistega, s komer solidarizirajo.

Če povzamem, solidarnost pomeni graditev skupnosti, utemeljene na vrednotah protirasizma, in na avtonomen način (brez države, tržnih odnosov in velikih humanitarnih organizacij). Solidarnost je del samoorganiziranega življenja v skvotih (v številnih evropskih mestih, tudi Ljubljani) in načelo vzpostavljanja (začasnih) varnih prostorov na balkanski migracijski poti (Atene, Podgorica, Beograd, Šid, Sarajevo, Velika Kladuša itd.) in drugod (na primer nekdanji samoorganizirani kamp v Calaisu).

V nadaljevanju bom pokazala državno uničevanje solidarnostnih odnosov in praks. Nadzorovani in preganjani niso le begunci, temveč tudi tisti, ki skupaj z njimi gradijo začasne varne cone, »prostore življenja«, kot se je izrazil eden od migrantov v Calaisu (Tazzioli in Walters, 2019, str. 186). Preganjani so tudi aktivisti in aktivistke, ki rešujejo pred utopitvijo v Sredozemskem morju ali pred potiskanjem ljudi v libijske zapore, in zagovornice mednarodne zaščite. 


\section{Kriminalizacija solidarnosti: razcep v humanitarizmu in vzpostavljanje sovražnega okolja}

Vlasta Jalušič (2019) v raziskavi kriminalizacije solidarnosti v Sloveniji, Avstriji, Italiji, na Hrvaškem in Madžarskem ugotovi, da oblast preganja neodvisne, avtonomne skupine in s tem oži delovanje in odgovornost civilne družbe, ustrahuje zagovornike človekovih pravic in javno razvrednoti delo solidarnostnih skupin. Oblast solidarnost prikaže kot zločin. Kot pišeta Tazzioli in Walters $(2019$, str. 181), je preganjanje avtonomnih iniciativ povzročilo razcep znotraj humanitarizma: medtem ko so neodvisna gibanja in dejavnosti posameznic napadene in preganjane, prorežimske humanitarne in mednarodne organizacije vladajo na področju migracij bolj kot kadarkoli prej. Tako sta varnostnizacija in humanitarizem, ko gre za velike prodržavne organizacije, vse bolj prepletena. Nazorna primera sta, kako begunske kampe vodi International Organisation for Migration v Bosni in Hercegovini in kako se je pomoč razdeljevala v času policijsko-humanitarnega koridorja v Sloveniji. Velike humanitarne organizacije (Rdeči križ, UNHCR idr.) so prostovoljkam in prostovoljcem dala avtoritarna navodila, avtonomne skupine pa niso imele dostopa do beguncev (Lunaček Brumen in Meh 2016; Zorn, 2016).

V letih od 2015 do aprila 2019 je bilo v državah EU proti posameznim osebam sproženih 158 kazenskih postopkov in 16 proti nevladnim organizacijam (Vosyliūtė in Conte, 2019). Peticija »Mi smo evropska dobrodošlica« (We're welcoming Europe, b.d) pa s 146.195 podpisi, vloženimi pri Evropski komisiji, zahteva nasprotno; da oblasti nehajo kriminalizirati osebe in skupine, ki pomagajo beguncem in migrantom. Peticija zahteva tudi, da države aktivno podprejo tiste, ki migrantkam in migrantom ponudijo svoj dom za skupno bivanje.

Omenjene številke kazenskih postopkov so le vrh ledene gore državnega preganjanja prostovoljk, saj preganjanje obsega tudi celoten diskurz sumničenja, diskreditiranja in preprečevanja dostopa do stika z begunkami in begunci (Carrera, Vosyliūtė, Smialowski, Allsopp in Sanchez, 2018; Tazzioli, 2018). Učinka takega nadzora sta uničevanje spontanih odzivov na prihod beguncev in občutek odvečnosti obojih, tako domačinov, ki se solidarizirajo z migranti, kot migrantov (Jalušič, 2019). Z drugimi besedami, države ne le nadzorujejo in ovirajo mobilnost migrantov, temveč vzpostavljajo sovražno okolje tudi za tiste, ki migrante podpirajo (Webber, 2018). Preganjanje neodvisnih skupin in posameznic vodi v kršenje pravice do svobode govora, svobode združevanja in političnega delovanja (Carrera, Vosyliūtè, Smialowski, Allsopp in Sanchez, 2018; Vosyliūtè in Conte, 2019). V nadaljevanju te trditve ponazorim s primeri iz Slovenije in drugih držav.

Slovenska nacionalna stranka (SNS) je na tožilstvo podala kazensko ovadbo proti Pravno-informacijskem centru nevladnih organizacij zaradi informiranja migrantov o postopku za mednarodno zaščito na slovensko-hrvaški meji (STA, 2019). Ta nevladna organizacija je bila najprej (leta 2018) napadena v medijih $\mathrm{z}$ argumentom, da pomaga pri ilegalnih prehodih meje. Mediji so poročali v okviru policijske logike. Stranka SNS je organizacijo ovadila zgolj na podlagi medijskih poročil. 
Istega leta (2019) je policija $\mathrm{z}$ istimi argumenti (tihotapljenje migrantov) podala na tožilstvo predlog za pregon socialnih delavk, ki so na slovenski strani meji preprečile policijsko potiskanje. Več kot leto dni se je vlekel predkazenski postopek, preden so ugotovili, da ni elementov kaznivih dejanj (Lilija, 2020). Še večjo gonjo je doživela hrvaška organizacija Are You Syrious (2018). Hrvaška policija je leta 2018 ovadila prostovoljca, ki je poskušal preprečiti policijsko potiskanje družine z več otroki. To je bila družina, ki ji je umrl otrok, ko jih je hrvaška policija potisnila proti Srbiji konec leta 2017. Hrvaško ministrstvo za notranje zadeve je zahtevalo prepoved delovanja organizacije Are You Syrious, zaporno kazen za prostovoljca in 43.000 evrov kazni. Sodišče zahtev ministrstva sicer ni v celoti sprejelo, a je spoznalo prostovoljca krivega za pomoč »ilegalnim migrantom «. Tak način delovanja oblasti zakriva nelegalnost policijskih potiskanj in odgovornost hrvaške policije za smrt otroka. Poleg tega v širši javnosti vzbudi dvome o legitimnosti zagovorništva in solidarnosti z ljudmi na poti.

Slovenska in hrvaška zakonodaja sta skladni z evropskimi zakonodajnimi smernicami (t. i. facilitator package) ${ }^{4}$, ki solidarnostne prakse enačijo s tihotapljenjem. Materialna korist ni nujen element za kvalifikacijo kaznivega dejanja, ko gre za pomoč »tujcem, ki nimajo dovoljenja za vstop v RS « (3. odstavek 308. člena Kazenskega zakonika Republike Slovenije, 2012; več o tem v Zorn, 2021). Enako je v Italiji, na Malti, v Grčiji in drugod. S pomočjo protitihotapske zakonodaje oblasti preganjajo posameznice in skupine, ki rešujejo človeška življenja pred utopitvijo. Več nevladnih organizaciji in samoorganiziranih posadk je reševalo migrante iz Sredozemskega morja, potem ko se je leta 2014 končala enoletna italijanska vojaško-humanitarna reševalna operacija Mare Nostrum, ki je 150.000 ljudi obvarovala smrti v Sredozemskem morju (Cusumano, 2018).

To operacijo naj bi nadomestila Frontexova akcija Triton. Ne le da Frontex bolj nadzoruje meje, kot rešuje ljudi, ampak so ministri za notranje zadeve članic EU ter vodje Frontexa vedno bolj začeli napadati in pravno preganjati samoorganizirane skupine. Italijanske in malteške oblasti ladjam, ki rešujejo ljudi, ne dovoljujejo pristanka v njihovih pristaniščih, zato so reševalne akcije nevzdržne. Kapitanki Carola Rackete (Sea Watch 3) in Pia Klemp (Iuventa 10) sta bili aretirani z grožnjo do 15 oziroma 20 let zapora z obtožbami »pomoči in omogočanja ilegalnih migraciji« (ABC News, 2019). Čeprav Pii Klemp (2019) grozi do 20 let zapora, je v javnem govoru »Zakaj se borim za solidarnost « povedala:

Vredno je bilo [rešiti vsakega človeka, ki smo ga rešili] in to bi storili spet.

To bi storili, ne posledicam [kriminalizaciji] navkljub, ampak še toliko bolj prav zaradi tega.

Zlasti ta zadnji stavek meri na to, da problem kriminalizacije solidarnosti ni pravni, temveč politični. To pomeni, da so zakonodaja in pravni mehanizmi uporabljeni za ohranjanje globalnih neenakosti in preprečevanje solidarnostnih praks.

4

»Facilitator package « sestavlja: Facilitaton Directive (Direktiva Sveta 2002/90/EC z dne 28 novembra 2002 opredeljuje pomoč pri neavtoriziranem vstopu, tranzitu in bivanju, OJ L 328) in Framework Decision (Svet EU o krepitvi kazenskega pregona za preprečevanje pomoči neavtoriziranega vstopa, tranzita in bivanja, 2002/946/JHA, OJ L 328) (Carrera, Vosyliūtè, Smialowski, Allsopp in Sanchez, 2018). 
Sarah Mardini (2020), berlinska študentka, ki je v Nemčijo pribežala iz Sirije po balkanski poti, se je vrnila v Grčijo in tam kot prostovoljka delala dve leti. Na grški obali je prispelim beguncem dajala vodo in odeje ter prevajala. Grške oblasti so jo obtožile tihotapljenja, pripadanja kriminalni združbi in vohunjenja. V svojem javnem nastopu je povedala, da ji je sto dni, preživetih v preiskovalnem zaporu, zadalo večje rane kot vojna v Siriji in potovanje v potapljajočem se gumijastem čolnu iz Turčije v Grčijo. Vsem prostovoljcem pa oblast tako sporoča, kam jih njihove solidarnostne prakse lahko pripeljejo.

Vztrajanje pri avtonomnih solidarnostnih iniciativah lahko privede v simbolno in dejansko »nalezljivost ilegalizacije«, izraz, ki sta ga v svoji raziskavi uporabili Marta Stojić Mitrović in Ela Meh (2015). V socialnem delu ugotovitev »nalezljivosti« ni nova, saj so socialne delavke pogosto stigmatizirane podobno kot ljudje, s katerimi delajo (denimo na področju duševnega zdravja, zmanjševanja škode pri uživanju nedovoljenih drog ipd.). Nova je dejanska (formalna), ne le simbolna »nalezljivost«, kot kažejo primeri državnega preganjanja prostovoljk in prostovoljcev.

\section{Sklep}

Institucijo državnih mej sem prikazala v več dimenzijah: kot policijski nadzor na meji, vprašanje nasilja, potiskanj in onemogočanja mednarodne zaščite; kot izraz globalnih neenakosti; in v povezavi z odporniškim gibanjem, avtonomijo migracij in solidarnostjo z migrantkami in migranti.

Pokazala sem, da so nadzor mej, varnostnizacija in ilegalizacija problem tako za avtonomijo migrantk in migrantov kot avtonomijo socialnega dela. Ti procesi institucionalizirajo neenakost. Primer je 5. člen Zakona o socialnem varstvu (2019), ki dostop do storitev zameji z osebnimi statusi ljudi. V članku sem raziskala problematičnost varnostnizacije, da bi ta diskurz in ukrepe razločili od socialnodelovnih, saj je to prvi pogoj, da se socialne delavke in delavci pridružimo migrantskim bojem za enako dostojanstvo in enake pravice. Varonostnizacija namreč ni nujno ločena od delovanja humanitarnih organizaciji. Z drugimi besedami, ljudje potrebujejo in zahtevajo enakost, ne (le) kruha (Božič, 2019).

Pri razlagi antagonizma nadzora meje in pravice do mednarodne zaščite sem uporabila pojem organizirane hipokrizije. Policijska retorika pravice do mednarodne zaščite legitimira zavračanje tistih, ki so videni kot ekonomski migranti in migrantke.

Nasilne meje so sovražno okolje tako za migrante oziroma begunce kot za tiste domačine, ki se z njimi solidarizirajo. Politike integracije pa so paradoksne, saj države ustvarjajo sovražno okolje, potem pa v tem sovražnem in formalno izključujočim okoljem, v katerem je legalizacija bivanja in zaposlovanja mnogim nedostopna, načrtujejo ukrepe integracije (Fućak, 2017). Prostori in odnosi solidarnosti se upirajo družbenemu konsenzu rasizma, varnostnizacije in sovraštva, zato so aktivistke in aktivisti tarče državnega pregona, tako kazenskega kot pregona v širšem pomenu (zastraševanja, razvrednotenja, izčrpavanja in oviranja dostopa do begunk in beguncev). Namen kriminalizacije je zamejevanje solidarnostnih protirasističnih praks in ustvarjanje družbene klime, v 
kateri naj bi vsak izmed nas postal čuvar meje (Dadusc in Mudu, 2020). Tako kot vselej v zgodovini je protirasistični boj naporna, trasformativna in kriminalizirana praksa.

Naj za konec dodam, da pogled $\mathrm{v}$ zgodovino pomaga videti boje za enakopravnost kot pomembno politično delo, kot civilno nepokorščino in bojkot zakonov, ki so zatiralski. Zakonodaja je legalizirala suženjstvo in rasno segregacijo v ZDA, apartheid v Južnoafriški republiki, konec koncev tudi nacisti niso kršili tedaj veljavnih zakonov, ko so preganjali, zapirali in pobijali Jude (Silva, 2019). Tako tudi danes ne gre le za vprašanje (ne)spoštovanja zakonodaje; ključni so boji za enakost - enake pravice in enako dostojanstvo ljudi v lokalnem in globalnem kontekstu.

\section{Viri}

ABC News (2019). Migrant rescue ship capitan Pia Klemp rejects award from Paris. 23. avgust 2019. Pridobljeno 9. 11. 2020 s https://abcnews.go.com/International/migrant-rescue-ship-captain-pia-klemp-rejects-award/story?id=65122208

Amnesty International Slovenia (2018). Push-backs and denial of access to asylum: findings of the research mission in Velika Kladuša and Bihać, June 2018. Pridobljeno 27. 12. $2019 \mathrm{~s}$ https://www.amnesty.si/media/uploads/files/Slovenia\%20-\%20Push-backs\%20and\%20denial\%20of\%20access\%20to\%20asylum\%2C\%20Amnesty\%20International(1).pdf

Are You Syrious (2018). When governments turn against volunteers: the case of AYS. Pridobljeno 4. 3. $2020 \mathrm{~s}$ https://medium.com/are-you-syrious/ays-special-when-governments-turn-against-volunteers-the-case-of-ays-81fcfe0e80e7

Balibar, É. (2007). Mi, državljani Evrope? Meje, država, ljudstvo. Ljubljana: Založba Sophia.

Border Violence Monitoring Network (b.d.). Pridobljeno 1.6. 2020 s https://www.borderviolence.eu/

Božič, K. (2019). Za učinkovito varovanje schengenske meje. Večer, 11. 7. 2018. Pridobljeno 10. 11. $2020 \mathrm{~s}$ https://www.vecer.com/slovenija/za-ucinkovito-varovanje-schengenske-meje-6518568

Carrera, S., Vosyliūtè, L., Smialowski, S., Allsopp, J., \& Sanchez, G. (2018). Fit for purpose? The Facilitation directive and criminalisation of humanitarian assistance to irregular migrants: 2018 update. Pridobljeno 9. 4. 2020 s https://www.europarl.europa.eu/RegData/etudes/ STUD/2018/608838/IPOL_STU(2018)608838_EN.pdf

Cusumano, E. (2018). Migrant rescue as organized hypocrisy: EU maritime missions offshore Libya between humanitarianism and border control. Cooperation and Conflict, 22 (I), 2-22.

Dadusc, D., \& Mudu, P. (2020). Care without control: the humanitarian industrial complex and the criminalisation of solidarity. Geopolitics. Pridobljeno 4. 5. 2020 s https://www.tandfonline.com/doi/full/10.1080/14650045.2020.1749839

Delovna skupina za azil (2020). Tiskovna konferenca 24. 1. 2020, Sloga, Metelkova 6, Ljubljana.

Dragoš, S. (2016). Socialna država in solidarnost. Teorija in praksa, 53 (posebna številka), 148173.

ECCHR (2020). Croatia to answer the European Court of Human Rights. Pridobljeno 3. 6. $2020 \mathrm{~s}$ https://www.ecchr.eu/en/case/croatia-to-answer-to-european-court-of-human-rights/

Evropski parlament (2020). Seja odbora LIBE, 27. januarja 2020 od 15.00 do 18.30. Pridobljeno 1. 3. $2020 \mathrm{~s} \mathrm{https://www.europarl.europa.eu/streaming/?event=20200127-1500-COMMITTEE-}$ -LIBE

Fassin, D. (2012). Humanitarian reason: a moral history of the present. Los Angeles: University of California Press.

Federici, S. (2019). Re-enchanting the world: feminism and the politics of the commons. Oakland: PM Press. 
Flaker@Boj za, V. (2012). Direktno socialno delo. Ljubljana: Založba *cf.

Freire, P. ([1968] 2019). Pedagogika zatiranih. Ljubljana: Krtina.

Fućak, V. (2017). Uporaba neformalnih prostorov za integracijo beguncev v Ljubljani (diplomsko delo). Ljubljana: Fakulteta za socialno delo.

Galtung, J. (1969). Violence, peace, and peace research. Journal of Peace Research, 6(3), 167-191.

Hrvatin, A. (2016). Socialno delo v avtonomnih prostorih: vloga socialnega dela pri graditvi kontramoči. Ljubljana: Fakulteta za socialno delo.

Humphries, B. (2004). An unacceptable role for social work: implementing immigration policy. British Journal for Social Work, 34, 93-107.

Huysmans, J. (2000). The European Union and the securitization of migration. Journal of Common Market Studies, 38(5), 751-777.

Info Kolpa (2019). Poročilo o nezakonitih kolektivnih izgonih na slovensko-hrvaški meji. Časopis za kritiko znanosti, 278, 81-113.

IOM (2020). Missing migrants: tracking deaths along migratory routes. Pridobljeno 3. 5. $2020 \mathrm{~s}$ https://missingmigrants.iom.int/

Ivačič, M. (2019). Skupnostno kuhanje v avtonomnih prostorih (magistrsko delo). Ljubljana: Fakulteta za socialno delo.

Jalušič, V. (2019). Criminalizing "pro-immigrant" initiatives: reducing the space of human action. Dve domovini, 49, 105-123.

Jones, R. (2017). Nasilne meje. Ljubljana: Zložba *cf.

Kazenski zakonik Republike Slovenije (2012). Ur. l. RS, št. 50/12 - uradno prečiščeno besedilo, 6/16 - popr., 54/15, 38/16, 27/17, 23/20 in 91/20.

Klemp, P. (2019). Why I fight for solidarity. TEDxBerin 2019. Pridobljeno 20. 1. $2020 \mathrm{~s}$ https:// www.ted.com/talks/pia_klemp_why_i_fight_for_solidarity

Lilija, A. (2020). Kriminalizacija migracij in solidarnosti (diplomsko delo). Ljubljana: Fakulteta za socialno delo.

Lipovec Čebron, U., \& Zorn, J. (2016). Avtonomija in nadzor migracij v evropskih »tamponskih conah «. Dve domovini, 43, 61-75.

Lunaček Brumen, S., \& Meh, E. (2016). » Vzpon in padec « koridorja. Nekaj refleksij o spremembah na balkanski migracijski poti od poletja 2015. Časopis za kritiko znanosti, 44 (264), 21-45.

Mardini, S. (2020). How / was arrested for handing out blankets to refugees. TEDxLondonWomen. Pridobljeno 4. 10. $2020 \mathrm{~s}$ https://www.ted.com/talks/sarah_mardini_how_i_was_arrested_ for_handing_out_blankets_to_refugees

Medium (2020). AYS special: Italian court stops deportation to Slovenia, meanwhile pushbacks continue. Pridobljeno 26. 8. 2020 s https://medium.com/are-you-syrious/ays-special-italian-court-stops-deportation-to-slovenia-meanwhile-pushbacks-continue-a0370c30cd02

Ministrstvo za notranje zadeve RS (2018). Ministrica: $v$ Sloveniji ne odrekamo pravice do mednarodne zaščite, 7. 9. 2018. Pridobljeno 11. 10. 2020 s http://mnz.arhiv-spletisc.gov.si/si/novinarsko_sredisce/novica/10383/index.html

Online Etymology Dictionary (b.d.). Solidarity (n.). Pridobljeno 10. 11. 2020 https://www.etymonline.com/search?q=solidarity

Papadopoulos, D., \& Tsianos, V. S. (2013). After citizenship: autonomy of migration, organisational ontology and mobile commons. Citizenship Studies, 17(2), 178-196.

Regvar, U. (2018). Poročilo o ugotovitvah in opažanjih o izvajanju postopkov vračanja in spoštovanja načela nevračanja (non-refoulement). Ljubljana: Pravno-informacijski center nevladnih organizacij. Pridobljeno 10. 11. 2020 s http://pic.si/wp-content/uploads/2018/07/ Poroc\%CC\%8Cilo-o-izvajanju-postopkov-vrac\%CC\%8Canja-PIC.pdf

Silva, G. (2019). Migrational disobedience: the fetishization of immigration law. A publication of the Radical Philosophy Assocciation. 18. januar 2019.

Sporazum med Vlado Republike Slovenije in Vlado Republike Hrvaške o izročitvi in prevzemu oseb, katerih vstop ali prebivanje je nezakonito (2006). Ur. l. RS, mednarodne pogodbe št. 
8/06. Pridobljeno 10.11. 2020 s http://www.pisrs.si/Pis.web/pregledPredpisa?id=ZAKO4624

STA (2019). V SNS zaradi pomoči migrantom ovadili direktorico Pravno-informacijskega centra. Delo, 24. maj 2019. Pridobljeno 10. 11. 2019 s https://www.delo.si/novice/slovenija/v-sns-zaradi-pomoci-migrantom-ovadili-direktorico-pravno-informacijskega-centra-188149.html

Stojić Mitrović, M., \& Meh, E. (2015). The reproduction of borders and the contagiousness of illegalisation: a case of a Belgrade Youth Hostel. Glasnik etnografskog instituta, 63(3), 623-639.

Tazzioli, M. (2018). Crimes of solidarity: migration and containment through rescue. Radical Philosophy 2.01. Pridobljeno 3. 2. 2020 s https://www.radicalphilosophy.com/commentary/ crimes-of-solidarity

Tazzioli, M., \& Walters, W. (2019). Migration, solidarity and the limits of Europe. Global Discourse, 9(1), 175-90.

UNCHR Slovenija (b.d.). Spremljanje postopkov na meji. Pridobljeno 27. 1. 2019 s https://www. unhcr.org/si/spremljanje-postopkov-na-meji-2

Urad Vlade RS za oskrbo in integracijo migrantov (2020). Število oseb s priznano mednarodno zaščito v Republiki Sloveniji po letih. Pridobljeno 19. 5. $2020 \mathrm{~s} \mathrm{https://www.gov.si/assets/}$ vladne-sluzbe/UOIM/STATISTIKA/Januar-2020/Osebe-s-priznano-mednarodno-zascito-po-letih-12-2019-v3.pdf

Varuh človekovih pravic (2018). Vmesno (s)poročilo o aktivnostih in ugotovitvah Varuha o očitkih policistom, da zavračajo možnosti podajanja prošenj za mednarodno zaščito. Pridobljeno 11. 10. 2018 s http://www.varuh-rs.si/medijsko-sredisce/sporocila-za-javnosti/novice/detaj//vmesno-sporocilo-o-aktivnostih-in-ugotovitvah-varuha-glede-ocitkov-zavracanja-moznosti-podajan/

Vosyliūtè, L., \& Conte, C. (2019). Crackdown on NGOs and volunteers helping refugees and other migrants. ReSoma. Pridobljeno 17. 3. $2020 \mathrm{~s} \mathrm{http://www.resoma.eu/sites/resoma/resoma/fi-}$ les/policy_brief/pdf/Final\%20Synthetic\%20Report\%20-\%20Crackdown\%20on\%20NGOs\%20 and\%20volunteers\%20helping\%20refugees\%20and\%20other\%20migrants_1.pdf

Webber, F. (2018). The legal framework: when law and morality collide. V L. Fekete, F. Webber, \& A Pettitt Edmond (ur.), Humanitarianism: the unacceptable face of solidarity. London: Institute for Race Relations (str. 7-21)

We are welcoming Europe (b.d.). Pridobljeno 5. 5. 2020 s https://www.migpolgroup.com/index. php/portfolio-item/welcoming-europe/

Zakon o socialnem varstvu (2019). Ur. l. RS, št. 28/19.

Zaviršek, D. (2017a). The humanitarian crisis of migration versus the crisis of humanitarianism: current dimensions and challenges for social work practice. Social Work Education. Pridobljeno 15. 9. $2020 \mathrm{~s}$ http://dx.doi.org/10.1080/02615479.2017.1303043

Zaviršek, D. (2017b). »Stultifera navis « na balkanski begunski poti. Dve domovini, 45, 45-60.

Zorn, J. (2006). Od izjeme do norme: centri za tujce, pridrževanje in deportacije. Časopis za kritiko znanosti, 34(226), 54-73.

Zorn, J. (2016). Social work with refugees at the Schengen border: »...but they are the same people as we are... «. Critical and radical social work, 4(1), 121-125.

Zorn, J. (2021). Evropski mejni režim: tihotapljenje ljudi in paradoks kriminalizacije solidarnosti. Dve domovini. V tisku. 